Pontifícia Universidade Católica $_{\text {Do Rio de Janeiro }}$

Carolina Valente de Oliveira

Prática policial e ordem moral: um estudo da relação moradores-polícia em uma comunidade em processo de pacificação

Dissertação de Mestrado

Dissertação apresentada ao Programa de PósGraduação em Estudos da Linguagem da PUC-Rio como requisito parcial para obtenção do título de Mestre em Letras/Estudos da Linguagem.

Orientadora: Profa. Maria do Carmo Leite de Oliveira

Rio de Janeiro, Março de 2016 


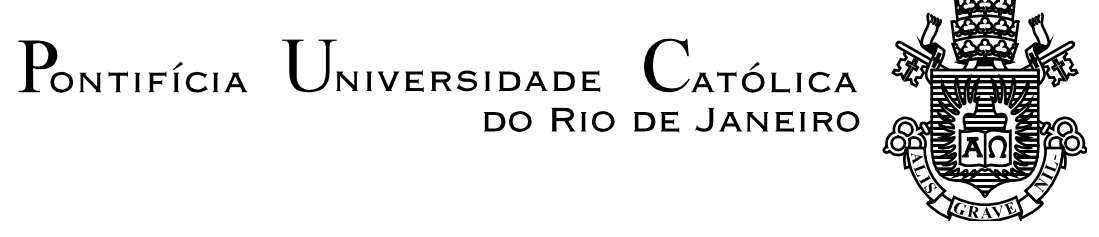

Carolina Valente de Oliveira

\title{
Prática policial e ordem moral: um estudo da relação moradores-polícia em uma comunidade em processo de pacificação
}

\begin{abstract}
Dissertação apresentada como requisito parcial para obtenção do grau de Mestre pelo Programa de Pós-Graduação em Estudos da Linguagem da PUCRio. Aprovada pela Comissão Examinadora abaixo assinada.
\end{abstract}

Profa. Maria do Carmo Leite de Oliveira

Orientadora

Departamento de Letras - PUC-Rio

Profa. Maria das Graças Dias Pereira

Departamento de Letras - PUC-Rio

Profa. Maria Claudia Pereira Coelho

UERJ

Profa. Denise Berruezo Portinari

Coordenadora Setorial do Centro de Teologia

e Ciências Humanas - PUC-Rio

Rio de Janeiro, 04 de março de 2016. 
Todos os direitos reservados. É proibida a reprodução total ou parcial do trabalho sem autorização da universidade, da autora e do orientador.

\section{Carolina Valente de Oliveira}

Graduou-se em Letras (Português/Inglês) na Universidade Federal do Rio de Janeiro (UFRJ) em 2011. Foi aprovada no ano de 2013 no processo seletivo de alunos do mestrado em Estudos de Linguagem da PUC-Rio.

Ficha Catalográfica

Oliveira, Carolina Valente de

Prática policial e ordem moral: um estudo da relação moradores polícia em uma comunidade em processo de pacificação / Carolina Valente de Oliveira; orientadora: Maria do Carmo Leite de Oliveira. - 2016.

$80 \mathrm{f} . ; 30 \mathrm{~cm}$

Dissertação (mestrado) - Pontifícia Universidade Católica do Rio de Janeiro, Departamento de Letras, 2016.

Inclui bibliografia

1. Letras - Teses. 2. Interação polícia-cidadão. 3. Unidade de polícia pacificadora. 4. Categoria de pertença e categorização. 5. Moralidade. I. Oliveira, Maria do Carmo Leite de. II. Pontifícia Universidade Católica do Rio de Janeiro. Departamento de Letras. III. Título. 


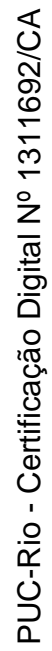

Para minha mãe e avó, Julimar e Adelina,

por todo apoio e carinho 


\section{Agradecimentos}

À minha orientadora, Maria do Carmo Leite de Oliveira, que serve de exemplo na busca pelo conhecimento de forma a contribuir para o desenvolvimento da sociedade. Agradeço por todo estímulo e confiança que através de sua garra, competência, simplicidade e generosidade fazem com que cresçamos como profissionais e cidadãos.

Aos amigos e companheiros do grupo de pesquisa: Amanda, Rony e Carla. Sem a ajuda de vocês essa jornada seria ainda mais difícil. As contribuições intelectuais e o ombro amigo foram de importância sem igual.

A todos os professores que compõem o quadro docente do programa de pósgraduação em Estudos de Linguagem da PUC-Rio, especialmente à Maria das Graças Dias Pereira, Liliana Cabral, Erica dos Santos Rodrigues e Liana de Andrade Biar.

À Comissão Examinadora que com todo carinho e cordialidade aceitou participar da minha defesa de mestrado.

À minha mãe e avó, Julimar e Adelina (in memoriam), que sempre estiveram ao meu lado. Não há formas suficientes de agradecer por tudo que fizeram por mim.

Aos meus padrinhos, Maria do Rosário e João Batista, que sempre me apoiaram e incentivaram.

Ao meu namorado, Leonardo, que sempre foi porto seguro nessa longa jornada.

Aos funcionários da secretaria de Letras, especialmente a funcionária Chiquinha, por sua competência e por serem exemplos de atenção e gentileza.

Aos participantes que sempre acreditaram no potencial dessa pesquisa.

A todos os amigos e familiares que, ao longo desse trabalho, me cercam de carinho. 


\section{Resumo}

Oliveira, Carolina Valente de; Oliveira, Maria do Carmo Leite. Prática policial e ordem moral: um estudo da relação moradores-polícia em uma comunidade em processo de pacificação. Rio de Janeiro, 2016. 80p. Dissertação de mestrado - Departamento de Letras, Pontifícia Universidade $\begin{array}{lllll}\text { Católica do Rio de } & \text { Janeiro. }\end{array}$

Este trabalho tem como foco as relações entre polícia-cidadão em uma comunidade em processo de pacificação. À luz de uma abordagem etnometodológica, buscou-se investigar como o conhecimento organizado em torno da categoria policial orientou a descrição que os moradores fazem daqueles que são membros do que se denomina Polícia Pacificadora. Com base nos conceitos de categoria de pertença e categorização de pertença, verificamos que o processo de categorização do policial que atua em uma Unidade de Polícia Pacificadora- UPP se realizou a partir do que é provido pelo conhecimento de senso comum como atividades atreladas à categoria de policial. É com base na descrição do que seria direito e dever do policial que os moradores constroem o significado de bom e mau policial. Os resultados mostram também que a categorização dos policiais é feita através de um processo de contraste com outras subcategorias militares e até com a categoria traficante. Através desse processo, percebe-se que, para os moradores, o novo modelo de polícia se afasta das expectativas de uma polícia focada no cidadão e no bem da comunidade, o que leva, em alguns casos, a uma inversão da categoria de mocinho e bandido.

\section{Palavras-chave}

Interação polícia-cidadão; Unidade de Polícia Pacificadora; Categoria de Pertença e Categorização; Moralidade. 


\section{Abstract}

Oliveira, Carolina Valente de; Oliveira, Maria do Carmo Leite (Adivisor). Police Practice and moral order: a study of residents-police relationship in a Peace process community. Rio de Janeiro, 2016. 80p. MSc. Dissertation - Departamento de Letras, Pontifícia Universidade Católica do Rio de Janeiro.

This research focuses on the relationship between police-citizen in a community in peace process. In light of the ethnomethodological approach, we sought to investigate how organized knowledge around the police category guided the description that residents produce in relation to those who are members of what is called Pacification Police. Based on the concepts of membership category and membership categorization, we find that the police categorization process that operates in a Pacifying Police Unit (UPP) was held from what is provided by the common sense knowledge as activities tied to the police category. It is based on the description of rights and duties of the police that the residents build the meaning of a good and a bad police officer. The results also show that the categorization of the police is made by a contrastive process with other military sub-categories and even with the trafficker category. Through this process, it is clear that, for the residents, the new police model departs from the expectations of a police focused on the citizen and on the well-being of the community, which leads, in some cases, a reversal of the good guy category and trafficker category.

\section{Keywords}

Police-citizen Interaction; Pacifying Police Unit; Membership Category; Membership Categorization; Morality. 


\section{Sumário}

1. Introdução

2. Fundamentação teórica 14

2.1. A perspectiva etnometodológica 14

2.2. O conceito de Categoria pertença e Categorização de pertença 16

2.2.1. O Dispositivo de Categoria de pertença 16

2.2.2. Categorização de pertença 20

2.3. Moralidade 23

3. Metodologia 31

3.1. Natureza da pesquisa 31

3.2. O universo da pesquisa 31

3.3. A constituição do corpus 36

3.4. Procedimentos analíticos $\quad 38$

4. A Categoria de incumbência policial 39

4.1. Direitos e deveres do policial 39

4.1.1. Deveres do policial $\quad 39$

4.2. Direitos do policial $\quad 47$

4.2.1. A abordagem 47

4.2.2. O estabelecimento da ordem 54

5. O contraste entre tipos de categorização de pertencimento 58

5.1. O policial de UPP e outras subcategorias de policial 58

5.2. Policiais e traficantes $\quad 65$

6. Considerações finais 73

7. Referências bibliográficas 76 
"Eu sou um intelectual que não tem medo de ser amoroso, eu amo as gentes e amo o mundo. E é porque amo as pessoas e amo o mundo, que eu brigo para que a justiça social se implante antes da caridade".

Paulo Freire 